\title{
VARIA \\ LAS ESCULTURAS ITALIANAS DEL TRANSPARENTE DE LA CATEDRAL DE TOLEDO
}

Desde el mismo momento en que Castañeda dedica su hiperbólico panegírico «a el Nuevo Magnífico Transparente» se plantea el hecho de la existencia en él de "cinco perfectísimas Estatuas de marmol blanco que... pueden oy servir a la obra de corona. Esmero... de algún dignísimo Prelado" ${ }^{1}$. Las esculturas, pues, serían anteriores a la obra de Narciso Tomé y provendrían del intento de otro prelado por enriquecer la girola de la Catedral entorno a la ventana tras la cual se veía la pequeña estancia del Sacramento. Hoy, gracias a las obras de Nina Ayala Mallory ${ }^{2}$ y, de modo muy especial, de José María Prados ${ }^{3}$, los Tomé han dejado de ser la incógnita del barroco español de que hablaba Chueca Goitia en $1962{ }^{4}$. La obra de los Tomé, de Narciso sobre todo que es el miembro más destacado de la familia, se nos ha ido desvelando, pero la complejidad del Transparente, pieza que según Pevsner figura entre las obras de categoría universal ${ }^{5}$, es tal, que aun quedan jirones de su historia artística e iconográfica por desentrañar.

Con este trabajo pretendemos dar un paso más para el conocimiento de obra tan espléndida aclarando el enigma de las esculturas italianas que alberga, dando a conocer quién las encarga y de dónde y en qué momento llegan a Toledo. Como ya hemos visto por Castañeda la existencia de estatuas italianas en la obra del Transparente era algo que estaba en la tradición de la Catedral y el error está en el desconocimiento del momento en que llegan y de cuales sean exactamente las esculturas que se exportan. José María Prados ha hecho un minucioso resumen de todas las opiniones que a estas esculturas se han referido aunque, como veremos, no llega a la conclusión correcta ${ }^{6}$. La noticia documental exacta y precisa es muy posible que duerma en ese limbo de papeles amontonados que, tantas veces comentamos, se guardan sin catalogar en la $\mathrm{Ca}$ -

1 De Castañeda, F. X.: Relación de los solemnes aparatos ... con que en la Imperial Ciudad de Toledo ... se celebró la colocación de Christo Sacramentado ... a el Nuevo Magnífico Transparente..., Toledo: por Pedro Marqués, Impresor del Rey Nuestro Señor, 1732.

2 Ayala Mallory, N.: "El Transparente de la Catedral de Toledo (1721-1732)», Archivo Español de Arte, n. ${ }^{\circ} 167$, 1969, pág. 255.

3 Prados, J. M.: "Las trazas del Transparente y otros dibujos de Narciso Tomé para la Catedral de Toledo", Archivo Español de Arte, n. ${ }^{\circ}$ 196, 1976, pág. 387 y Los Tomé una familia de artistas españoles del siglo XVIII, Madrid, Ed. de la Universidad Complutense, 1991.

4 Chueca Goitia, F.: «Narciso Tomé: una incógnita del Barroco Español», Goya, n. ${ }^{\circ}$ 49, 1962, pág. 12.

5 Pevsner, N.: Esquema de la arquitectura europea, Buenos Aires, Infinitivo, 1957.

6 Prados, J. M.: Las trazas del Transparente..., pág. 388. 
tedral de Toledo, y que nosotros, un tanto sumaria, hemos localizado en los Libros de Obra y Fábrica.

Los datos comienzan a fecharse el 25 de junio de 1677, ese día se paga a "Juan Martínez y Juan Pasq ${ }^{1}$, vecinos de Alicante, 137 doblones $\mathrm{y}^{\circ}{ }^{\circ}$ de a dos escudos... los quales an importado el porte de las cinco estatuas de marmol y un escudo de Armas del $\mathrm{Em}^{\circ} \mathrm{S}^{\mathrm{r}} \mathrm{Car}^{\mathrm{l}}$ Aragón desde Alicante a esta ciudad... y son del $\mathrm{S}^{\mathrm{r}} \mathrm{S}^{\mathrm{n}}$ Eugenio la una, $\mathrm{S}^{\mathrm{n}}$ Ildefonso, esperanza, fee y caridad y el escudo de armas». Del coste se nos informa muy poco después, el 1 de julio, día en que D. Lucas de Olarte, Receptor General de la Obra, pagaba en Madrid a un tal marqués Serra 269 doblones, un escudo y seis reales de plata $" \mathrm{p}^{\mathrm{r}}$ el coste $\mathrm{q}$ tuvieron las estatuas q son, S. Eugenio, S. Ildefonso, Fee, Esperanza y Caridad y el escudo de armas del $\mathrm{Em}^{0} \mathrm{~S}^{\mathrm{r}} \mathrm{Car}^{1}$ Aragón... de hacerlas en Genova y traerlas hasta Alicante». Y finalmente el 6 de agosto se indica que el mismo marqués Serra había recibido en Madrid 3.371 y $29 \mathrm{~m}^{\mathrm{s}}$ (?) y cinco dineros de $\mathrm{V}^{\mathrm{n}}$, «del coste q tuvieron de fletes y aderezos de manos y mitras en Alicante las estatuas y el escudo de armas» 7 .

Resumiendo, pues, estos datos, está claro que la noticia de existir en el Transparente cinco piezas italianas que ya aporta Castañeda ${ }^{8} \mathrm{y}$ fragmentariamente Ponz ${ }^{9}$, Parro ${ }^{10} \mathrm{y}$ otros diversos autores es cierta. También queda claro que su origen y realización es genovés y que el encargo y traída hasta Toledo se deben a iniciativa del cardenal D. Pascual de Aragón como ya indicó Monseñor Esténaga, posiblemente porque pudo encontrar algún dato que apuntase en ese sentido en la extensa biografía que dedicó a este cardenal ${ }^{11}$, y no al cardenal Portocarrero como insistentemente se venía sosteniendo. Curiosamente las obras llegaban a Toledo apenas tres meses antes de la muerte del Prelado y nunca debió llegar a verlas. Lógicamente estarían dedicadas al primitivo proyecto de Transparente que este prelado planeó y para el que contó con la partiticipación de Francisco Rizi, entonces pintor de la Catedral, que realizó dos trazas pagadas por Bartolomé Zumbigo el 27 de abril de $1672{ }^{12}$. Que estaban dedicadas para ser adosadas al muro del deambulatorio lo indica el no estar talladas por la espalda aunque, desde el sitio que hoy ocupan y las vemos, parecen de bulto redondo. Los Tomé contaron desde un primer momento con ellas y por esto ya aparecen colocadas en su lugar definitivo desde el primer proyecto ${ }^{13}$.

Nos encontramos, pues, con cinco magníficas obras genovesas que tenemos además perfectamente fechadas. Son por otra parte obras distintas de técnica del conjunto de esculturas del Transparente como ya apunta Nina Ayala Mallory ${ }^{14}$. Para su estudio pormenorizado nos encontramos con el problema de su ubicación a más que considerable altura, ello nos ha obligado a encaramarnos a lugares de difícil acceso que ha hecho especialmente ingrata la labor del fotógrafo y no hemos contado con el reposo necesario para trabajo tan delicado.

Las tres esculturas de las Virtudes Teologales coronan majestuosas el gran conjunto como se repite con tanta frecuencia en el remate de grandes retablos a todo lo largo del Renamiento y el Barroco internacional, y la pareja de los Santos Patronos de Toledo se ubican en el segundo

\footnotetext{
7 Archivo Catedral de Toledo: Libro de Obra y Fábrica de 1677, fol. 142.

8 De Castañeda, F. X.: Op. cit.

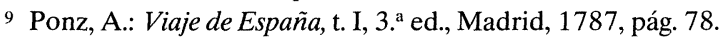

10 Parro, S. R.: Toledo en la mano, t. I, Toledo, IPIET, 1978, pág. 139.

11 De Esténaga y Echevarría, N.: El Cardenal Aragón (1626-1677), París, 1930, 2 ts., págs. 215, t. 1. ${ }^{\circ}$ y 345, t. $2 .^{\circ}$

12 Angulo Iñiguez, D.: «Francisco Rizi. Pinturas murales», Archivo Español de Arte, n. ${ }^{\circ}$ 188, 1974, pág. 361. En este trabajo D. Diego Angulo hace referencia a las trazas que Rizi realizó para la girola de la Catedral y las relaciona con las que también hizo para el retablo de la sacristía de El Escorial. La noticia la toma de Pérez Sedano, de sus Datos Documentales Inéditos..., pág. 107. El dato aparece en el Libro de Obra y Fábrica de 1672, está fechado el 27 de abril y dice textualmente: «En 27 de abril de 1672 se libró a Fran ${ }^{\text {co }}$ Rizi ... $11000 \mathrm{r}^{\mathrm{s}} \mathrm{v}^{\mathrm{n}}$ por un lienzo q ha pintado del retrato de Nra. Sra. del Sagrario de natural ... y dos trazas q ha echo $\mathrm{p}^{\mathrm{a}}$ la obra q se trata azer a las espaldas del SS $^{\text {mo }}$ Sacram $^{\text {to } . . . \prime ~}$

13 Prados, J. M.: Las trazas del Transparente..., pág. 397.

14 Ayala Mallory, N.: Op. cit., pág. 257.
} 

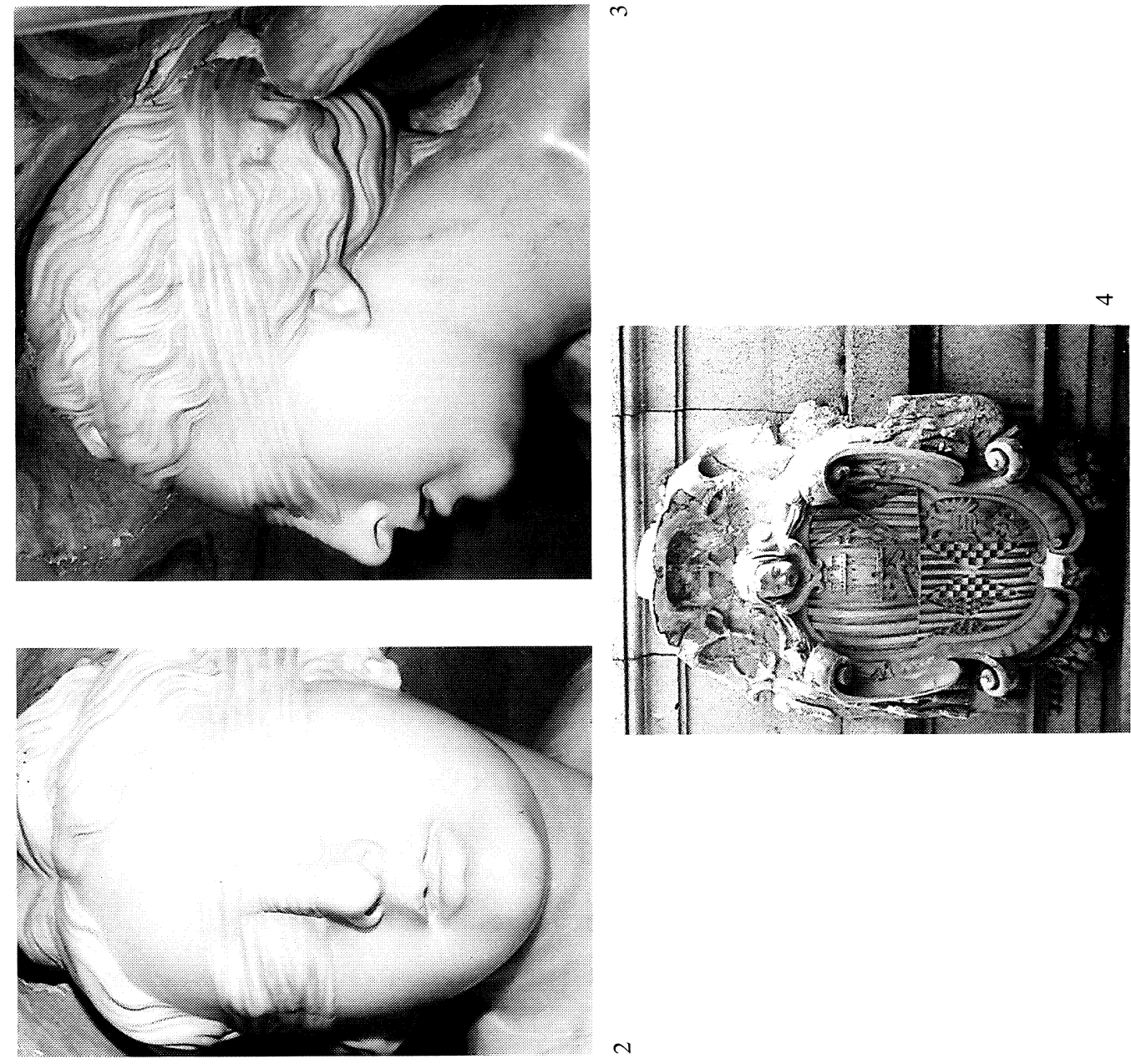

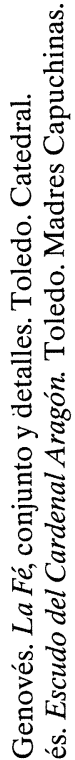

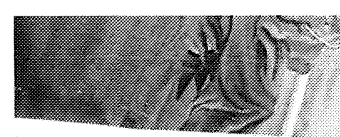

N

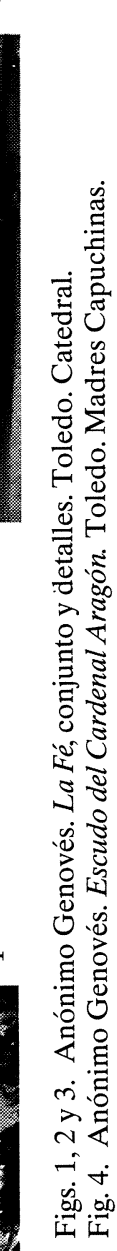

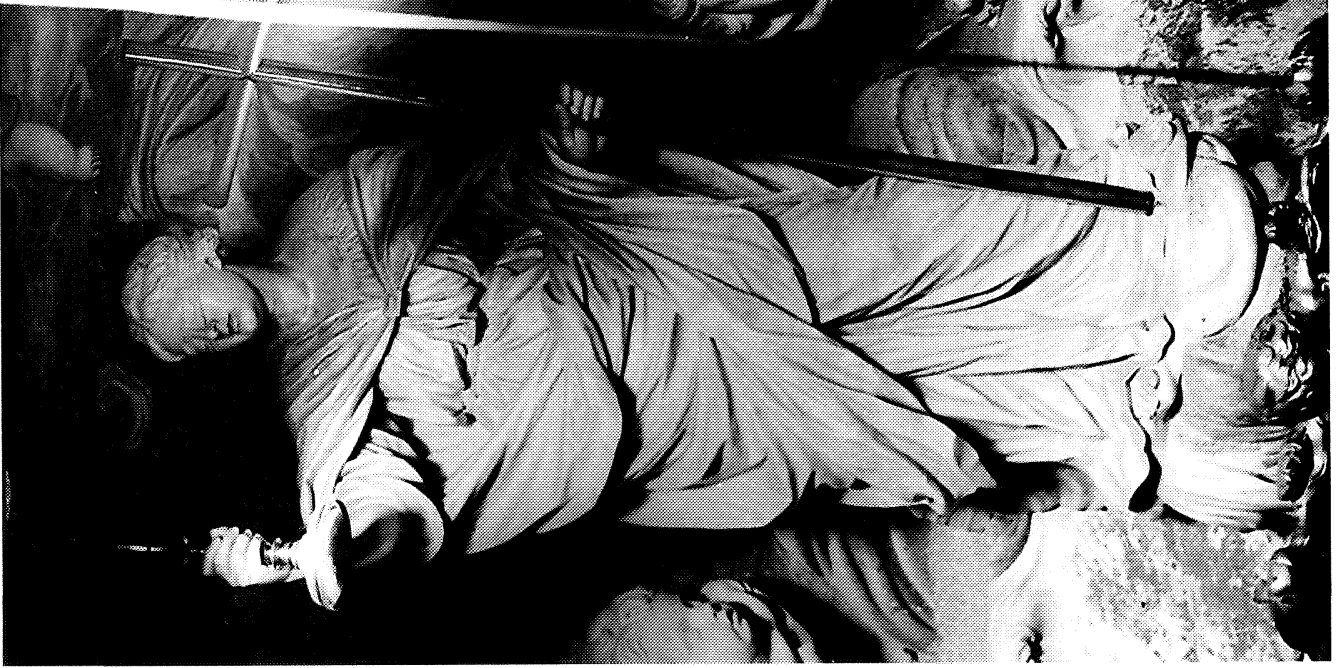


cuerpo, sobre la cornisa del entablamento del primero, en posición oblícula con respecto al eje central. Como seguidamente veremos, resulta claramente perceptible la diferencia de tratamiento entre las Virtudes y los Santos.

La efigie de la Fe se alza espléndida en el centro del remate del Transparente, empotrándose materialmente su cabeza en la bóveda que la acoge. Viste amplia túnica, de generoso escote, ceñida a la cintura, trabajada en infinitos pliegues menudos y aristados que casi apuntan a la técnica de paños mojados. Sobre los hombros, muy caído en el izquierdo, lleva amplio manto trabajado con la misma técnica aunque sí cabe con pliegues más largos y profundos. En la mano derecha alzada porta el simbólico cáliz, de bronce dorado, y en la izquierda sostiene una gran cruz del mismo material. La cabeza, única parte de la que hemos tenido la posibilidad de conseguir buena fotografía, es expresiva y de facciones delicadas. El perfil resulta de inspiración clásica, nariz alargada, boca pequeña entreabierta, como anhelante, y los ojos ocultos por ligera venda trabajada con tal suavidad que los párpados se insinúan bajo ella y que se anuda en la nuca. Bajo la barbilla muestra una muy característica papada. El abundante cabello lo lleva recogido y está trabajado en mechones largos y menudos. Se peina, además, de manera muy singular y que veremos en las tres Virtudes, con una especie de remate en gran copete que divide el peinado en dos zonas. Las piernas, en suave contrapposto, se alzan sobre una nube que vista de cerca se ve encajada en otra posterior de tratamiento distinto (figs. 1-3).

Al lado derecho, rematando el entablamento sobre una de las columnas, se alza la figura de la Esperanza que, colocada de frente en el espacio, gira suavemente la cabeza hacia la izquierda dirigiendo la mirada en esa dirección. Como la Fe viste túnica de redondo y gran escote y cruza el pecho con una doble banda en forma de aspa de refinado y convencional planteamiento. Las mangas, en parte recogidas sobre el brazo, son muy amplias, y la técnica con la que están tallados los ropajes es la misma menuda y quebrada en infinitos pliegues, de ricos efectos de luz, de la figura central. De manera elegante viste un manto que artificiosamente se anuda sobre el vientre creando efectos acaracolados de intenso barroquismo. Los brazos están doblados, el derecho lanzado sobre el espacio en actitud un tanto declamatoria y el izquierdo reposando, de manera suave y natural, sobre la simbólica áncora que también pisa con el pie del mismo lado en hermoso contrapposto. La cabeza es también similar a la de la figura de la Fe, cuello despejado, ligera papada bajo la barbilla, boca pequeña muy bien dibujada que en este caso aparece cerrada, y nariz larga menos recta y menos clásica que la de la figura central. Espléndido es el cabello, abundante y abarrocado, peinado en esas dos zonas comentadas, recogido parte en amplísimo moño y parte dejando caer generoso por la espalda en larguísima melena. La figura, como ocurre en el barroco, es susceptible de varios puntos de vista sólo abarcables desde zonas de muy difícil acceso. Espléndida, llena de majestad y gracia, se ve la escultua desde el lado izquierdo del triforio mudéjar de la Catedral (figs. 5, 6, 9).

En el lado opuesto se yergue la Caridad, tal vez la más hermosa de las tres figuras, que muestra una gracia y una delicadeza en el movimiento de los paños, en su rostro un tanto aniñado y en los niños que la acompañan que presiente claramente el recocó. Como las otras figuras se envuelve en vestido y manto, artificiosamente cruzado por delante, y deja libre el busto como acabando de amamantar al niño que porta en brazos en un movimiento un tanto inestable que le hace pegarse a su cuerpo y casi cogerse a uno de sus pechos. El otro niño, en el suelo, se abraza a sus piernas y entre los dos hay un gesto de acercamiento que les lleva a intercalarse unas frutas. Como ocurre con la figura de la Esperanza, el más hermoso punto de vista es el lateral izquierdo, tal como se ve desde el triforio de la girola (figs. 7, 8 y 10).

La belleza de las tres figuras nos hace lamentar la altura de su ubicación justificada en la iconografía del Transparente, pero es seguro que en el proyecto del siglo xviI se concibieron para ser vistas a menor altura del espectador. 


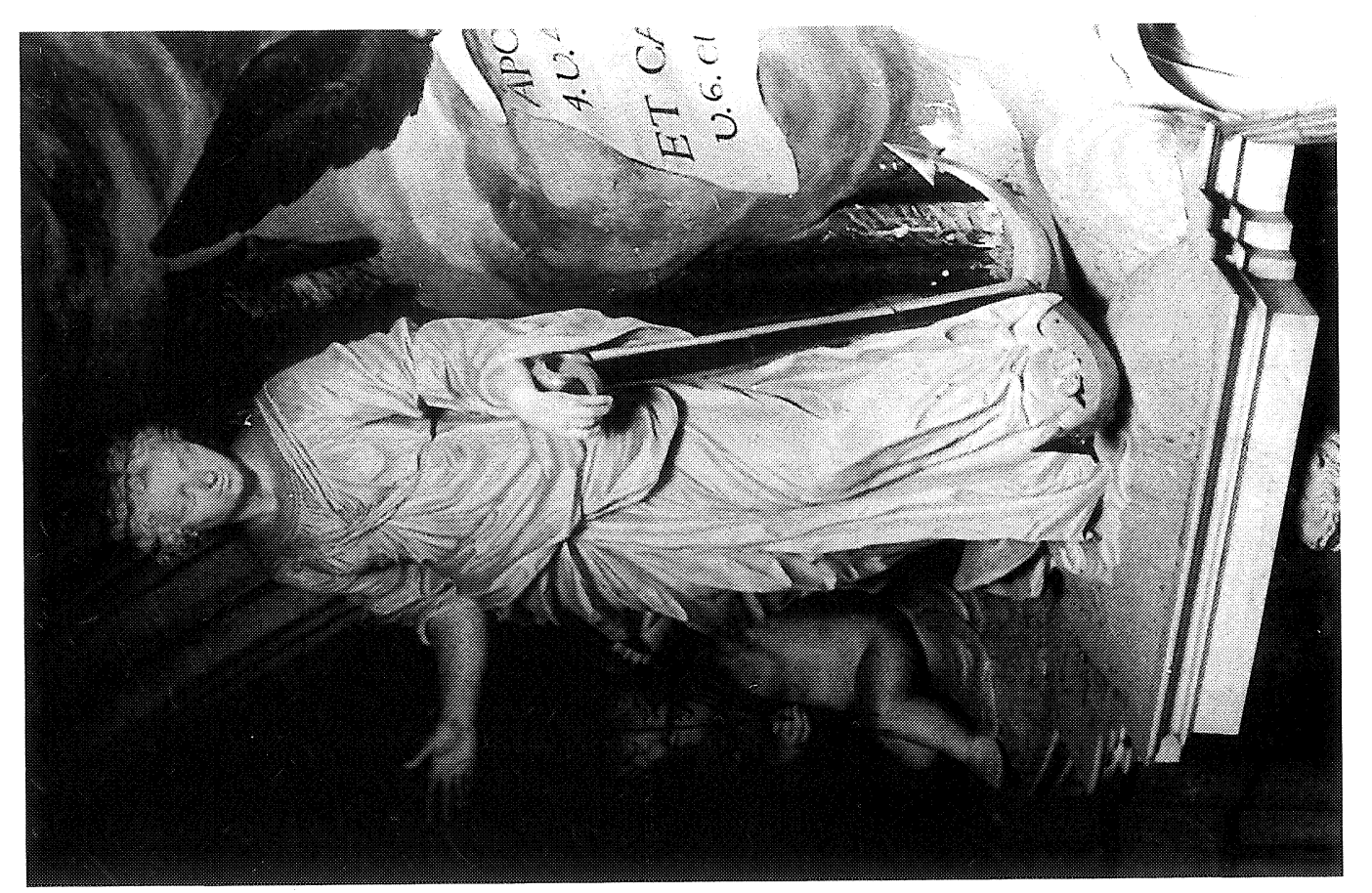

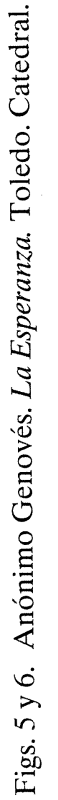

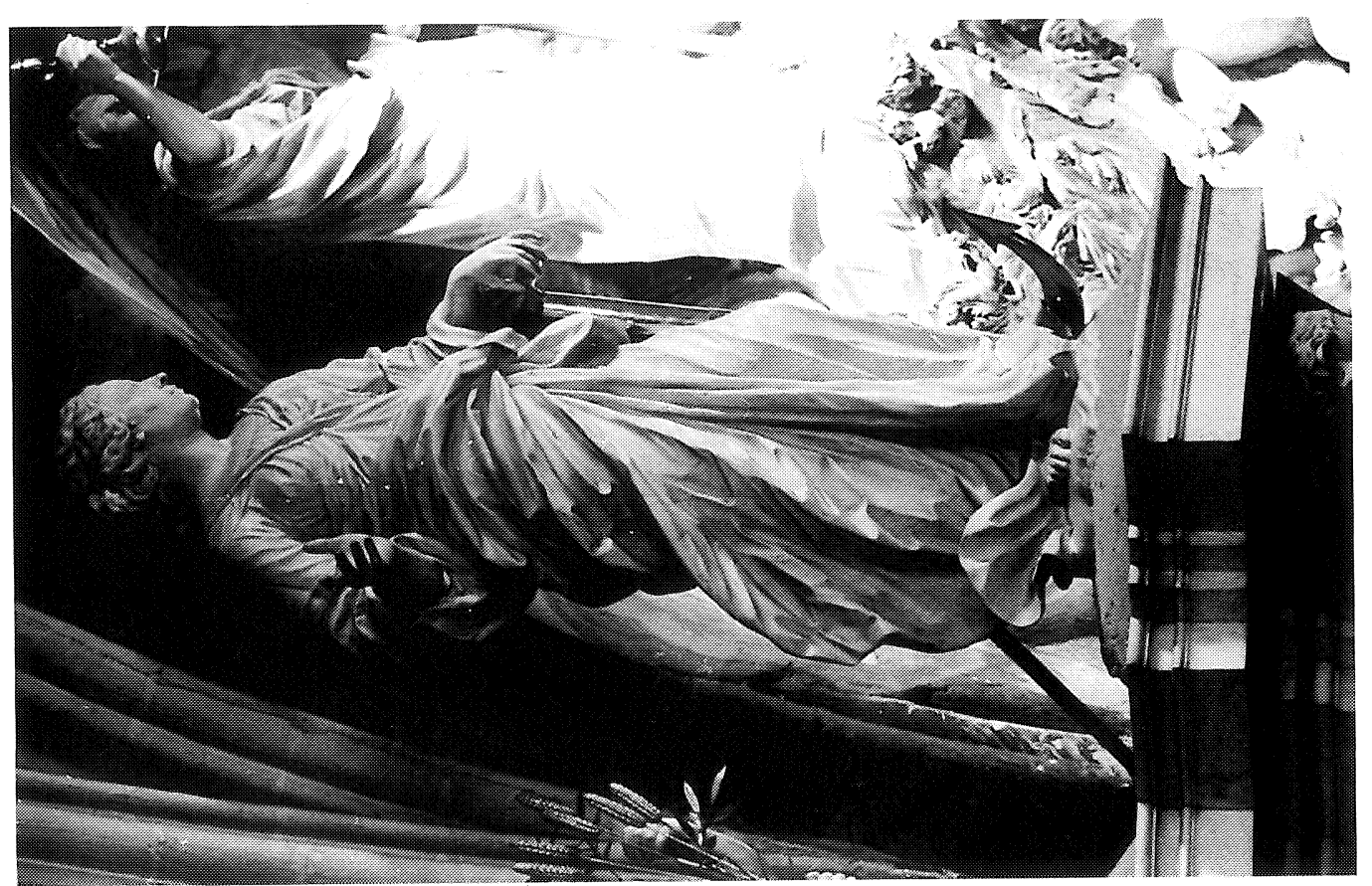


En la zona inmediatamente más baja, sobre el entablamento del primer cuerpo, se muestran los dos Santos toledanos, San Eugenio y San Ildefonso. Ambos vestidos de manera semejante con ropas episcopales, mitra sobre la cabeza y báculo en la mano izquierda. La parte más individualizada son sus rostros, viejo y barbado el San Eugenio, joven y barbilampiño el San lldefonso con un tratamiento de la piel del rostro como si de una epidermis táctil se tratara. San Eugenio abre los brazos y con la mano derecha bendice a los fieles. San Ildefonso aparece en actitud más desenfadada recogiéndose la capa pluvial, que le cruza por delante, con la mano derecha. Son figuras que distan de la belleza y gracia de las Virtudes, esculturas hechas por encargo, correctamente trabajadas, pero que parecen obedecer a recetas prefabricadas (figs. 10-13).

Como hemos visto, en el envío llega una sexta pieza que tal vez no fuese para la catedral sino para la más querida de las obras que en Toledo lleva a cabo el cardenal Aragón, el monasterio de Madres Capuchinas, su lugar de enterramiento ${ }^{15}$. En las dos fachadas exteriores de su iglesia, adosados al entablamento de las portadas, se incrustan sendos escudos de D. Pascual de Aragón de una gran belleza. Son escudos plenamente barrocos, de gran virtuosismo de talla, entroncados con la tradición manierista de placas de cuero y cabezas de monstruos. El que llega ahora, ¿se trata de alguno de estos dos escudos? (fig. 4), no nos atrevemos a pronunciarnos, pero todo este asunto de encargo de obras genovesas nos plantea un tema de lo más sugerente y al que ya, en repetidas ocasones, hemos aludido. De siempre se ha mantenido en la bibliografía tadicional sobre Toledo que las piezas escultóricas que adornan la fachada principal de las Capuchinas se debían al escultor Manuel Pereira, pero ya Jesús Urrea apuntó, por vez primera, que la Inmaculada de su hornacina distaba de la técnica de este escultor ${ }^{16}$. Estudiada la trayectoria del cardenal ya apuntamos a su vinculación genovesa que estos documentos, que ahora publicamos refuerzan ${ }^{17}$. De ser italiana, la Inmaculada de las Capuchinas sería algo anterior a las piezas de la Catedral, como muestran su mayor contención que incluso parecería anterior a la revolución escultórica que en Génova llevará a cabo Pierre Puget.

Nos encontramos, pues, ante un nuevo conjunto de obras genovesas de las que tantas llegaban a puertos levantinos, Valencia y Alicante sobre todo, donde como vemos se reparaban si habían tenido algún desperfecto en la travesía y, además, las tenemos fechadas con una gran precisión, en torno al año $1677^{18}$. Por desgracia nada concreto y seguro sabemos sobre su autor pero

15 Sobre el Monasterio de Madres Capuchinas se puede consultar De Villareal y Águila, Francisco: La Thebaida en poblado..., Madrid, Imprenta de Antonio Román, 1686. Martínez Caviró, B.: Conventos de Toledo, Madrid, Ed. El Viso, 1990, pág. 242. Al Monasterio y a su fundador le hemos dedicado los siguientes trabajos: «La correspondencia del Cardenal D. Pascual de Aragón a las Madres Capuchinas", Toletum, n. ${ }^{\circ}$ 26, 1991, pág. 9. "Inmaculadas firmadas por Claudio Coello y Miguel de Zayas en Toledo", Archivo Español de Arte, n. ${ }^{\circ} 228,1984$, pág. 383. "Unos bronces de Alessandro Algardi en el Monasterio toledano de Madres Capuchinas", Archivo Español de Arte, n. ${ }^{\circ} 249,1990$. "Dos obras de Pedro de Mena, o de su círculo inmediato, en el Monasterio de Madres Capuchinas de Toledo", BSAA, t. LVII, 1991 , pág. 437. "Una obra firmada por el pintor madrileño Simón León Leal y precisiones sobre otras pinturas existentes en Toledo", $B S A A$, t. LVIII, 1992, pág. 425.

16 Urrea, J.: «Introducción a la escultura barroca madrileña. Manuel Pereira», BSAA, t. XLIII, 1977, pág. 253.

17 También queremos expresar nuestra duda sobre la posibilidad de que los escudos de la iglesia de las Capuchinas sean anteriores en fecha, y que el escudo llegado en 1677 se destinara al proyecto de Transparente y se hubiese perdido, o aún se conserve, en alguna dependencia de la catedral.

18 Conocido es de siempre la gran cantidad de piezas genovesas llegadas a España en especial a las ciudades del Levante y Sur. De época muy cercana a estas piezas toledanas son las Virtudes del hospital de la Caridad de Sevilla, documentadas por D. Angulo, D. en: "Dos esculturas genovesas de 1682 en el hospital de la Caridad de Sevilla", Archivo Español de Arte, n. ${ }^{\circ}$ 196, 1976, pág. 453. Queremos también dejar constancia del gran parecido de la Virgen del Socorro del retablo de la capilla de los Genoveses de la catedral Vieja de Cádiz con piezas de los escultores G. B. Bianco o Tommaso Garvoalio en Génova. Recientemente se ha publicado un estudio de la escultura genovesa del siglo xviII en Cádiz debido a Aranda, C.; Hormigo, E. y Sánchez Peña, J. M.: Scultura lignea genovese a Cadice nel Settecento (Opere e Documenti), Génova, 1993. 

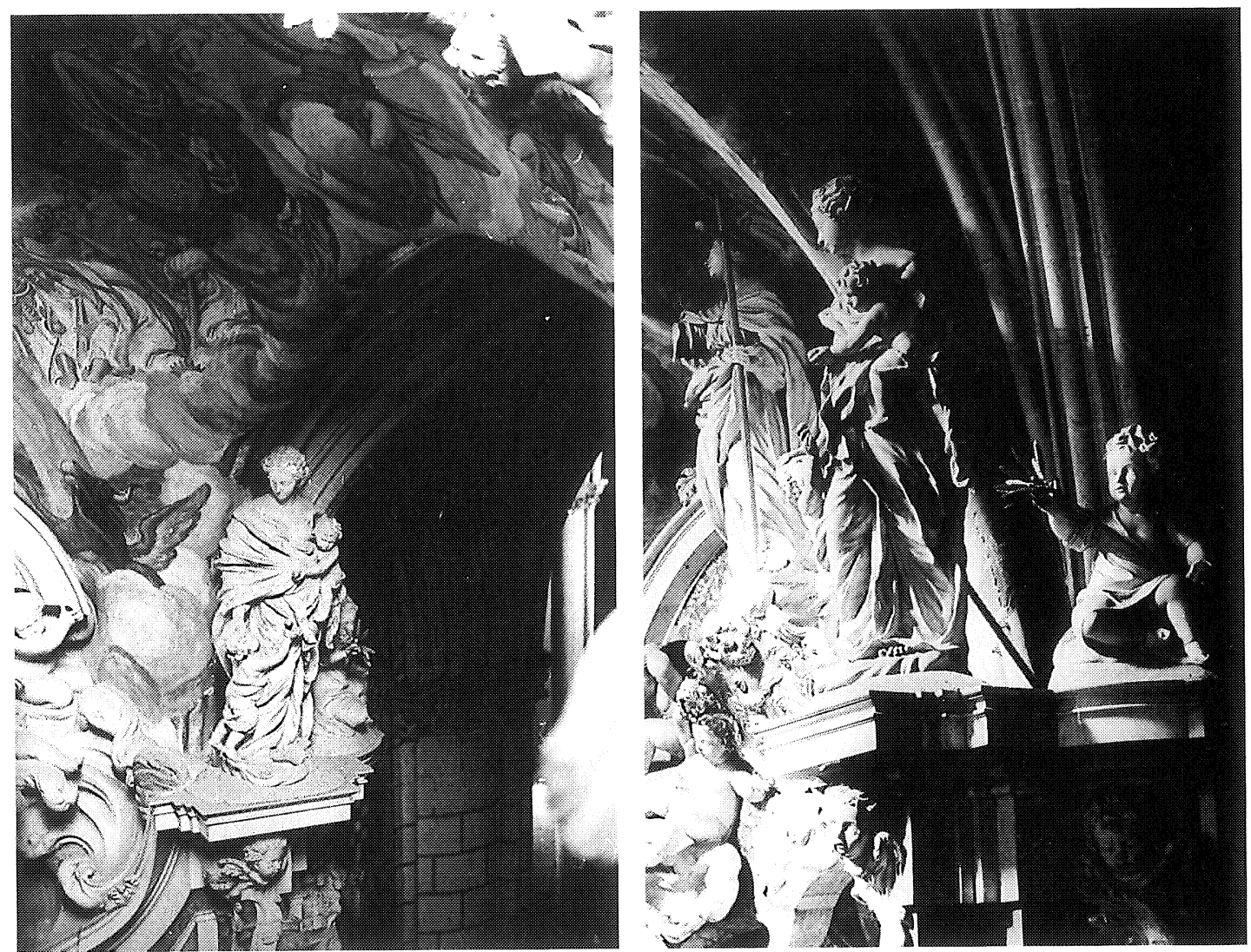

7
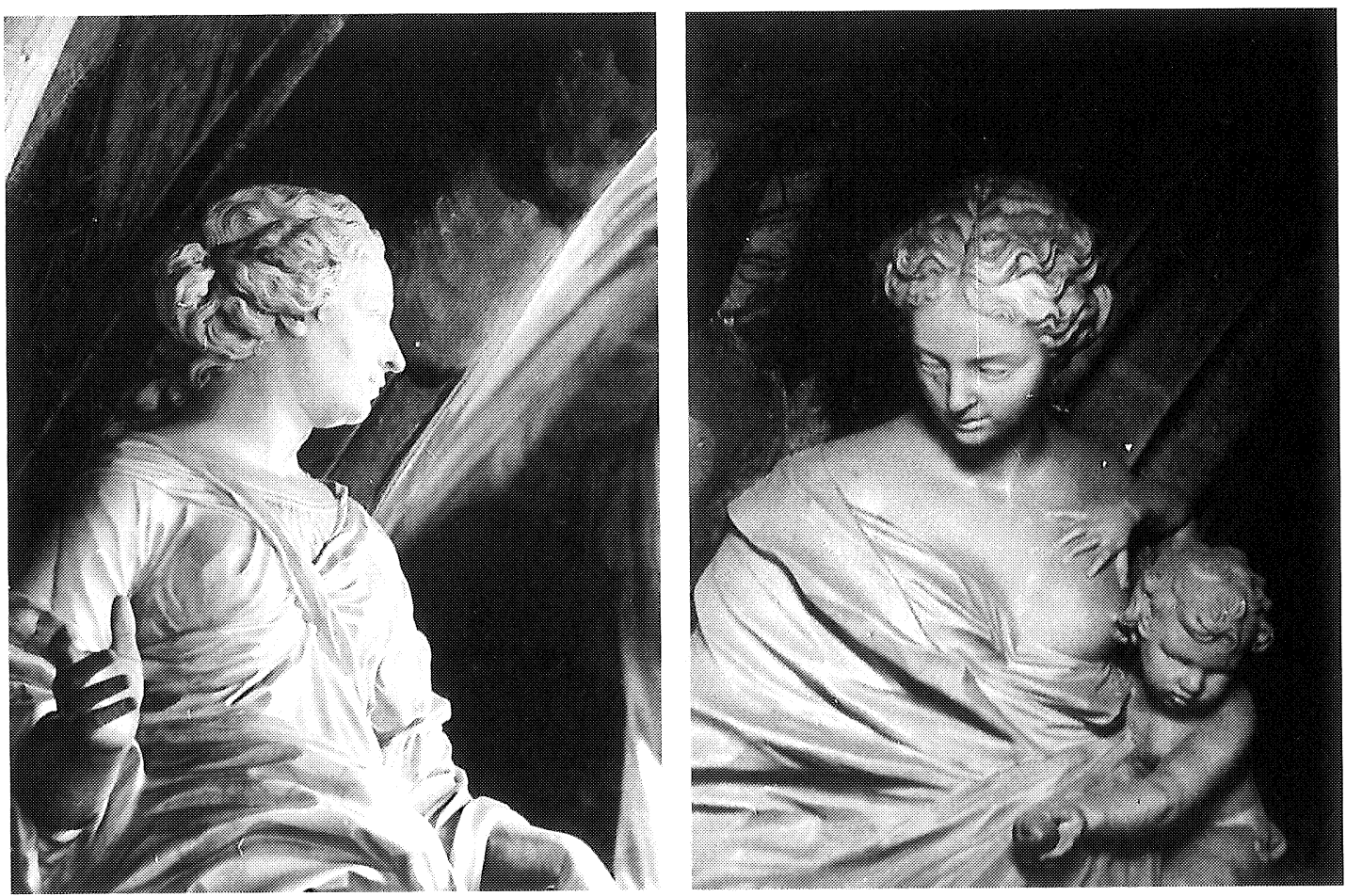

Figs. 7, 8 y 10. Anónimo Genovés, La Caridad, conjunto y detalle.

Fig. 9. Anónimo Genovés, La Esperanza, detalle. Toledo. Catedral. 
sí sabemos cual era el momento que vivía la escultura en Génova y quienes eran los escultores más destacados 19 .

La escultura genovesa había vivido toda la primera mitad del siglo xvir a costa de recetas aún manieristas, manteniendo tipos correctamente tallados pero faltos de personalidad y nervio, y sin haberse incorporado a las modernas corrientes barrocas que habían surgido en Roma. En esta situación aparece en 1660 en la ciudad ligur el marsellés Pierre Puget con el encargo de comprar mármoles, Génova era el gran puerto mediterráneo de embarco de mármoles italianos a los países europeos, y transportarlos a Francia para la obra del castillo de Vaux-Le-Viconte, por encargo de Foucquet responsable de las finanzas de Luis XIV ${ }^{20}$. Una serie de episodios de índole político y humano le supondrá una estancia de 10 años en la capital ligur. Puget había pasado cuatro años claves en Roma cultivando la pintura en el taller de Cortona y se había imbuido de lo mejor del barroco romano en las tres artes de la escultura, pintura y arquitectura. Como afirma Venanzio Belloni «se le llama el Bernini de Francia, aunque en realidad se le debería llamar El Cortona de la escultura: asimiló lo mejor de uno y otro artista» ${ }^{21}$. Con él, afirma el mismo historiador, Génova abría las puertas a la plena madurez del lenguaje barroco. Tuvo además la fortuna de encontrar en la ciudad colaboradores, discípulos y continuadores que seguirán sus enseñanzas a lo largo, al menos, de tres generaciones. Entre sus inmediatos discípulos destaca Filippo Parodi, formado en Roma y captado en Génova por la obra de Puget, Onorato Pellé, Daniele Solaro, Anselmo Quadro, etc., etc. Dada nuestra falta de un conocimiento especializado de la producción de la escultura genovesa, queremos simplemente dejar estas estatuas como obras de este momento y entroncadas con estos escultores, todos los cuales viven allí en el momento del encargo toledado. Pero no nos resistimos a manifestar nuestras simpatías por Anselmo Quadro, sus cariátides angélicas que sostienen el retablo-baldaquino de la Capilla Sauli de Santo Domingo, hoy en la iglesia de San Carlos de Génova, de hacia 1674, y sus alegorías de Virtudes de la iglesia de Jesús de la misma ciudad, presentan, a nuestro parecer, un tratamiento de paños de abarrocado movimiento, de aristas profundas de intenso claroscuro que, opinamos, se acercan de modo especial a las Virtudes toledanas. Además se ha dicho de Anselmo Quadro que lo que verdaderamente lo distingue es «la grazia e la novitá di espresione», frase que parece escrita, sin más, ante las tres estatuas de la Catedral de Toledo ${ }^{22}$.

Nada, sin embargo, podemos opinar de los Santos Arzobispos Eugenio e Ildefonso. Ya hemos dicho como los vemos faltos de fuerza, como si de algún modo hubiesen sido fabricados en serie. No hay en ellos ni rastro del apasionamiento del beato obispo Alejandro Sauli del Puget de la iglesia de Santa María de Carignano, y sólo hemos podido observar que la barba de San Eugenio presenta idéntico dibujo que la del San Pío V de Giacomo Molciano en la catedral de Alejandría al norte de Génova, aunque está lejos de su expresión de anhelo. A título anecdótico,

\footnotetext{
19 La bibliografía sobre la escultura genovesa del Barroco es hoy día muy amplia, nosotros hemos seguido, de manera muy especial, la obra de Belloni, V.: La grande scultura in marmo a Genova (secoli XVII e XVIII), GBG, 1988. Fundamental también para el conocimiento de la escultura genovesa es la obra de varios autores: La Scultura a Génova e in Liguria. Dal Seicento al Primo Novecento, II vol. Cassa di Risparmio di Génova e Imperia, Génova, 1988. Son especialmente interesantes para este trabajo el capítulo de los autores Boccardo, P. Lamera, F. Magnani, L. y Gavazza, E., titulado: $I l$ Seicento, artisti e committenti del Barocco. Aunque no se refiere a esta época, sino al siglo xvı, tiene un interés especial el capítulo de López Torrijos, R.: La scultura genovese in Spagna.

20 Sobre la trascendental figura de Pierre Puget es de gran importancia la citada obra de Belloni para el estudio de su vinculación genovesa. Especialmente interesante es el catálogo de la exposición dedicada al artista el pasado año en Marsella, con motivo del centenario de su muerte, titulado: Pierre Puget, Peintre, Sculpteur, Architecte, 1620-1694, Marseille, Musée de Beaux-Arts, 1994-1995. La revista Connaissance des Arts le acaba también de dedicar un espléndido número monográfico. Sobre el más importante de sus discípulos genoveses Filippo Parodi es de necesaria consulta la obra de Rotondi Briasco, P.: «Filippo Parodi», Quaderni del-L'Istituto di Storia dell'Arte, Universitá di Genova, 1962.

21 Belloni, V.: Op. cit., pág. 125.

22 Idem, pág. 179.
} 

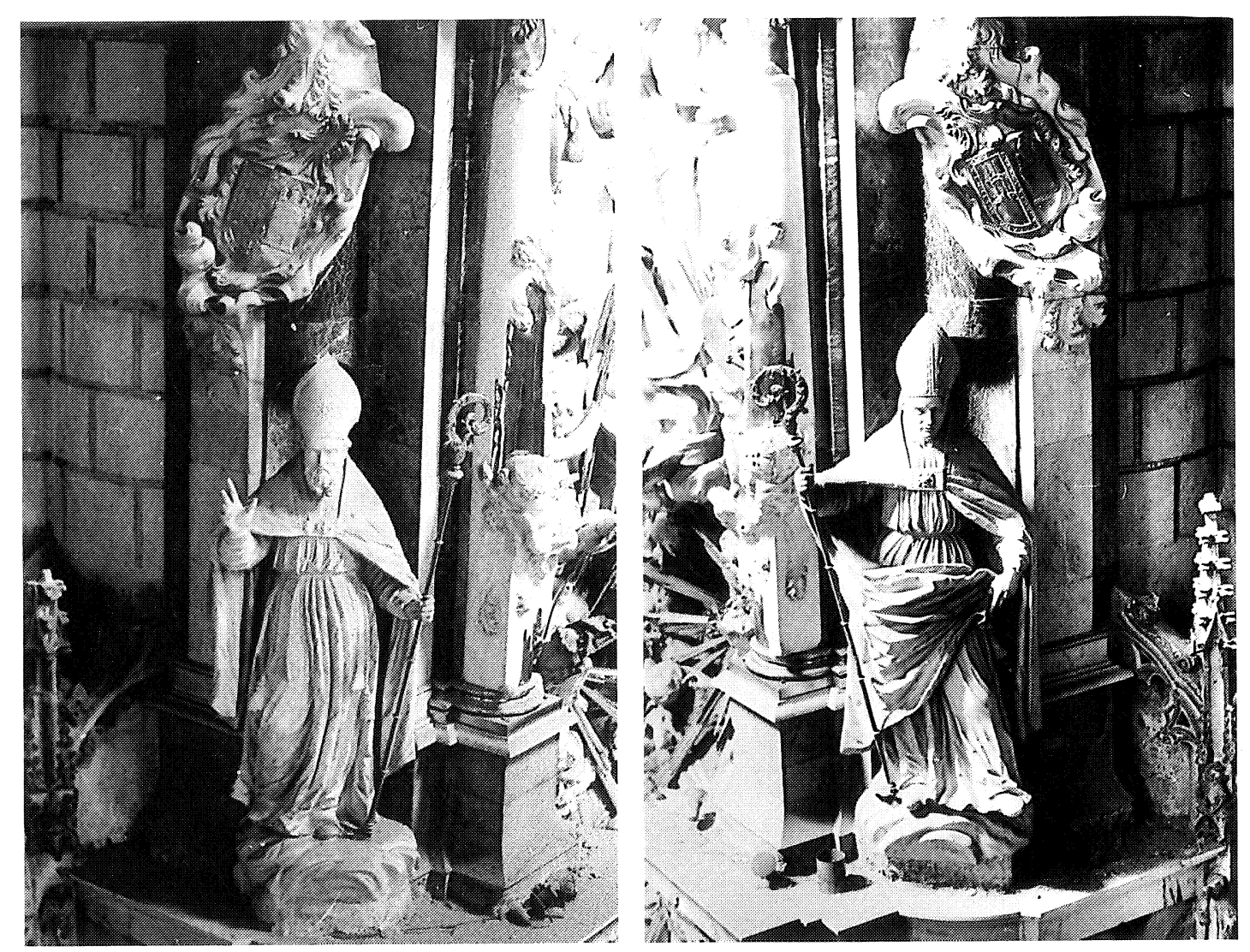

10
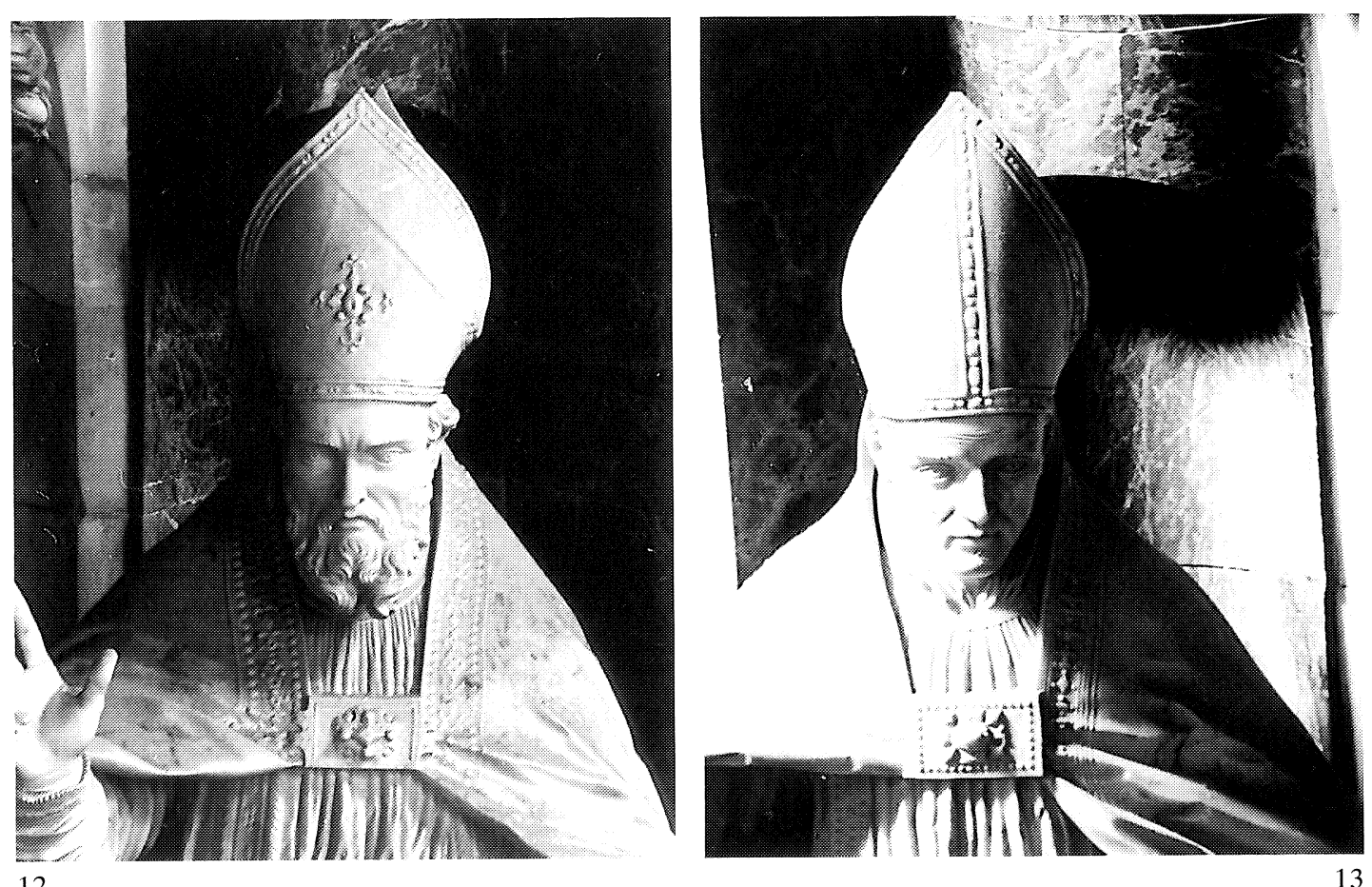

12

Figs. 10 y 12. Anónimo Genovés. San Eugenio, conjunto y detalle. Toledo. Catedral.

Figs. 11 y 13. Anónimo Genovés. San Ildefonso, conjunto y detalle. Toledo. Catedral. 
se observa con claridad como la mitra del San Eugenio ha sido restaurada en parte, en los talleres alicantinos, como indica la documentación. Más de taller sería el escudo de armas del cardenal Aragón sobre el que ya hemos indicado no nos atrevemos a pronunciarnos. Habrá que esperar la feliz circunstancia de que un documento aparecido en Toledo, Alicante o Génova nos desvele la paternidad de estas nuevas esculturas genovesas aparecidas en España.

Un último asunto en extremo problemático y sobre el que minuciosamente ha trabajado José María Prados, nos queda por plantear, el de la formación de Narciso Tomé, tema aún sin resolver y sobre el que se abren un gran número de interrogantes. Creemos que estas obras italianas influyen en su obra, las Santas Leocadia y Casilda del primer cuerpo del Transparente ofrecen elementos claramente tomados de ellas, a pesar de su más avanzada fecha y de su entronque ya con el rococó. Pero además, hay en la escultura genovesa del barroco una serie de elementos que aparecen, aunque con un evolucionado sello personal, en la obra de Narciso Tomé. Los símbolos angélicos del púlpito de la iglesia genovesa de San Siro, singularmente el ángel de San Mateo, y los ángeles que adornan los ángulos laterales del altar mayor de la capilla de Villa Cattaneo de una gracia plenamente rococó, por citar sólo dos ejemplos de los muchísimos que abundan, muestran unas alas que se adosan al mármol del fondo de manera sinuosa y tentacular al modo típico de un Tomé. Lo mismo cabe decir de la gracia, en realidad también rococó, de los ángeles laterales del altar mayor de la iglesia de San Siro, el que se ha dicho el más hermoso altar de Génova ${ }^{23}$, cuyo movimiento de danza parece pudieron inspirar figuras que Tomé repetirá, por ejemplo, en la peana de la custodia de la catedral ${ }^{24}$. Los espléndidos trabajos de mármoles de colores en solados y revestimientos de capillas también llevan a pensar en trabajos de Tomé que muy difícilmente pudo haberlos estudiado sin salir de la península. Nada definitivo podemos apuntar pero creemos que es una pista más a tener en cuenta al juzgar la obra española, inserta plenamente en el más selecto barroco europeo, de este genial artista toresano que enraizará en el mundo artístico y social toledano de la primera mitad del siglo xviII.

Juan Nicolau Castro

Dr. por la Universidad Autónoma

\section{NUEVAS OBRAS DE ANTONIO MOHEDANO Y FRANCISCO VARELA}

El estudio de la pintura sevillana del primer tercio del siglo xviI contó en 1985 con un riguroso trabajo de recopilación y catalogación realizado por Enrique Valdivieso y Juan Miguel Serrera ${ }^{1}$ que ha servido para que buena parte de los estudiosos de este período, puedan seguir avanzando en sus investigaciones.

Entre los artistas de este momento que se estudian, en la citada obra, se abordan las personalidades de Antonio Mohedano y Francisco Varela, artistas a cuyos catálogos podemos añadir ahora dos nuevas obras.

23 Belloni, Item, pág. 131.

24 Prados, J. M.: “El proyecto de Narciso Tomé para la peana de la custodia de la catedral de Toledo», Archivo Español de Arte, n. ${ }^{\circ} 201,1978$, pág. 101.

1 Valdivieso, E. y Serrera, J. M.: Pintura sevillana del primer tercio del siglo XVII, Madrid, CSIC, 1985. 